\title{
Microporous Silica Prepared by Organic Templating: Relationship between the Molecular Template and Pore Structure
}

\author{
Yunfeng Lu, ${ }^{\dagger, \dagger}$ Guozhong Cao, ${ }^{\dagger}$ Rahul P. Kale, ${ }^{\dagger}$ S. Prabakar, ${ }^{\dagger}$ \\ Gabriel P. López, ${ }^{*,+}$ and C. Jeffrey Brinker, ${ }^{*,+,}$ \\ Center for Micro-Engineered Materials, Department of Chemical \& Nuclear Engineering, \\ The University of New Mexico, Albuquerque, New Mexico 87131, and Direct Fabrication \\ Department 1831, Sandia National Laboratories, Albuquerque, New Mexico 87131
}

Received July 22, 1998. Revised Manuscript Received March 1, 1999

\begin{abstract}
Microporous silica materials with a controlled pore size and a narrow pore size distribution have been prepared by sol-gel processing using an organic-templating approach. Microporous networks were formed by pyrolytic removal of organic ligands (methacryloxypropyl groups) from organic/inorganic hybrid materials synthesized by copolymerization of 3-methacryloxypropylsilane (MPS) and tetraethoxysilane (TEOS). Molecular simulations and experimental measurements were conducted to examine the relationship between the microstructural characteristics of the porous silica (e.g., pore size, total pore volume, and pore connectivity) and the size and amount of organic template ligands added. Adsorption measurements suggest that the final porosity of the microporous silica is due to both primary pores (those present in the hybrid material prior to pyrolysis) and secondary pores (those created by pyrolytic removal of organic templates). Primary pores were inaccessible to $\mathrm{N}_{2}$ at $77 \mathrm{~K}$ but accessible to $\mathrm{CO}_{2}$ at $195 \mathrm{~K}$; secondary pores were accessible to both $\mathrm{N}_{2}$ (at $77 \mathrm{~K}$ ) and $\mathrm{CO}_{2}$ (at $195 \mathrm{~K}$ ) in adsorption measurements. Primary porosity decreases with the amount of organic ligands added because of the enhanced densification of MPS/TEOS hybrid materials as the mole fraction of trifunctional MPS moieties increases. Pore volumes measured by nitrogen adsorption experiments at $77 \mathrm{~K}$ suggest that the secondary (template-derived) porosity exhibits a percolation behavior as the template concentration is increased. Gas permeation experiments indicate that the secondary pores are approximately $5 \AA$ in diameter, consistent with predictions based on molecular simulations.
\end{abstract}

\section{Introduction}

The engineering of porosity in common materials such as silica and carbon is emerging as a new area of great technological and scientific interest. ${ }^{1-8}$ Materials with tailor-made pore sizes and shapes are particularly important in applications where molecular recognition is needed, such as shape-selective catalysis, molecular sieving, chemical sensing, and selective adsorption..$^{9-11}$

This paper reports on our continuing investigation of organic templating of amorphous microporous silica

\footnotetext{
* To whom correspondence should be addressed.

$\uparrow$ The University of New Mexico.

₹ Sandia National Laboratories.

(1) Zaman, J. Chakma, A. J. Membr. Sci. 1994, 92, 1-28.

(2) Beck, J. S.; Vartuli, W. J.; Roth, W. J.; Leonowicz, M. E.; Kresge, C. T.; Schmitt, K. D.; Chu, C. T. W.; Olson, D. H.; Sheppard, E. W.; McCullen, S. B. J. Am. Chem. Soc. 1992, 114, 10834-10843.

(3) Behrens, P. Adv. Mater. 1993, 5, 127-132.

(4) Kresge, C. T.; Leonowicz, M. E.; Roth, W. J.; Vartuli, J. C.; Beck, J. S. Nature 1992, 359, 710-712.

(5) Davis, M. E. Nature 1993, 364, 391-393.

(6) Chai, M.; Yamashita, Y.; Machida, M.; Eguchi, K; Arai, H. J. Membr. Sci. 1994, 97, 199-207.

(7) Chai, M.; Machida, M.; Eguchi, K.; Arai, H. J. Membr. Sci. 1994 $96,205-212$.

(8) Juibe, A.; Guizard, C.; Larbot, A.; Cot, L.; Fendler, A. G. J. Membr. Sci. 1993, 77, 137-153.

(9) Lu, Y.; Hang, L.; Brinker, C. J.; Niemczyk, T. M.; Lopez, G. P. Sensors Actuators $B$ 1996, 35, 1-5.
}

systems in which the templates are introduced as ligands covalently bonded to silica precursors. In the broadest sense, a template may be defined as a central structure about which a network forms in such a way that removal of the template creates a cavity with morphological and/or stereochemical features related to those of the template. As depicted in Figure 1, the idea is to form a dense hybrid organic/inorganic nanocomposite and remove the covalently bonded organic template ligands with no alteration of the inorganic framework. Ideally, the resultant porous microstructure would consist of a network of micropores with a size and shape comparable to those of the template ligand.

Hybrid nanocomposites are generally prepared by hydrolysis and condensation of mixtures of tetrafunctional alkoxides $\mathrm{Si}(\mathrm{OR})_{4}$ and organoalkoxysilanes $\mathrm{R}_{x}^{\prime} \mathrm{Si}(\mathrm{OR})_{4-x}$ under acidic or basic conditions. ${ }^{12-14}$ The covalently bonded organic ligand $\left(R^{\prime}\right)$ is usually nonhy-

(10) Cao, G.; Lu, Y.; Lopez, G. P.; Brinker, C. J. Adv. Mater. 1996, $8,588-591$

(11) Peterson, R. A.; Anderson, M. A.; Hill, C. G., Jr. J. Membr. Sci. 1994, 94, 103-109.

(12) Sanchez; Ribot, F. New J. Chem. 1994, 18, 1007-1047.

(13) Shea, K. J.; Loy, D. A.; Ewebater, O. J. Am. Chem. Soc. 1992 $114,6700-6710$

(14) Oviatt, H. W., Jr.; Shea, K. K. J.; Small, J. H. Chem. Mater. $1993,5,943-950$. 


\section{DISCLAIMER}

This report was prepared as an account of work sponsored by an agency of the United States Government. Neither the United States Government nor any agency thereof, nor any of their employees, make any warranty, express or implied, or assumes any legal liability or responsibility for the accuracy, completeness, or usefulness of any information, apparatus, product, or process disclosed, or represents that its use would not infringe privately owned rights. Reference herein to any specific commercial product, process, or service by trade name, trademark, manufacturer, or otherwise does not necessarily constitute or imply its endorsement, recommendation, or favoring by the United States Government or any agency thereof. The views and opinions of authors expressed herein do not necessarily state or reflect those of the United States Government or any agency thereof. 


\section{DISCLAIMER}

Portions of this document may be illegible in electronic image products. Images are produced from the best available original document. 
LIGAND O PORE

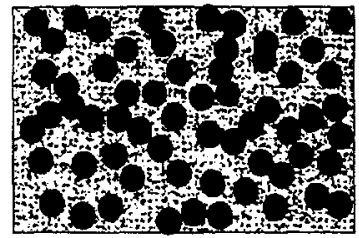

NOV 291999

faps tightly around the template) so that the pores created only by template removal.

(3) Template removal should be achieved without T Thatrix collapse so that the pores created preserve the diginal size and shape of the template.

(4) To ensure pore connectivity, it is necessary to exceed some percolation threshold of organic ligands.

Raman et al. ${ }^{16}$ prepared microporous silica membranes exhibiting high $\mathrm{CO}_{2}$ permeances and moderate $\mathrm{CO}_{2} / \mathrm{CH}_{4}$ selectivities using methyl ligands as templates by copolymerizing methyltrimethoxysilane (MTES) with tetraethyl orthosilicate (TEOS). However, as prepared hybrid MTES/TEOS materials are porous before removing the methyl ligands and no templating relationships were observed, probably because of ligand aggregation (phase separation) or unfavorable silica/ligand/solvent interactions. We have used other ligands (e.g., methacryloxypropyl from 3-methacryloxypropylsilane (MPS)) as templates that exhibit better silicaligand/solvent interactions to prepare highly dense hybrid materials prior to calcination to prepare microporous silica with controlled pore structure after removal of the templates. ${ }^{10}$ Here, we report our further detailed investigations on microporous materials derived from hybrid TEOS/MPS nanocomposites. By analysis of a molecular model and experimental data, we attempt to further understand the templating mechanism and to establish relationships between the size and volume fraction of the template ligand and the pore volume, pore size, and pore connectivity of the resulting templated microporous silica.

\section{Experimental Section}

The chemical precursors used were 3-methacryloxypropyltrimethoxysilane, $\mathrm{H}_{2} \mathrm{C}=\mathrm{C}\left(\mathrm{CH}_{3}\right) \mathrm{CO}_{2}\left(\mathrm{CH}_{2}\right)_{3} \mathrm{Si}\left(\mathrm{OCH}_{3}\right)_{3}$ (MPS, from PCR, Gainesville, FL), and tetraethyl orthosilicate, $\mathrm{Si}\left(\mathrm{OC}_{2} \mathrm{H}_{5}\right)_{4}$ (TEOS, from Kodak, Rochester, NY). Each MPS molecule contains one nonhydrolyzable organic ligand, $\mathrm{H}_{2} \mathrm{C}=\mathrm{C}\left(\mathrm{CH}_{3}\right)$ $\mathrm{CO}_{2}\left(\mathrm{CH}_{2}\right)_{3}$, which serves as a molecular template in the formation of microporous silica. The sol was prepared by mixing different amounts of TEOS $(1-x)$ and MPS $(x)$ with ethanol, $\mathrm{H}_{2} \mathrm{O}$, and $\mathrm{HCl}$ in a molar ratio of $1-x: x: 3.8: 5.1: 5.3 \times$ $10^{-3}(x<1)$ followed by reaction at $60{ }^{\circ} \mathrm{C}$ for $90 \mathrm{~min}$ at a stirring rate of approximately $400 \mathrm{rpm}$. Following dilution with two volumes of ethanol (e.g., $20 \mathrm{~mL}$ of ethanol was added to $10 \mathrm{~mL}$ of sol), sols were cast into Petri dishes and allowed to dry in air to obtain xerogels, which were then ground into a fine powder and calcined for $3 \mathrm{~h}$ in air at $150^{\circ} \mathrm{C}$ (heating rate $=1^{\circ} \mathrm{C} / \mathrm{min}$ ). Microporous silica was obtained by further heating the powders at $350^{\circ} \mathrm{C}$ for $3 \mathrm{~h}$ in an oxygen atmosphere (heating rate $1^{\circ} \mathrm{C} / \mathrm{min}$ ) to oxidatively pyrolyze the template ligands.

Prior to pyrolysis, hybrid xerogel specimens were characterized by nuclear magnetic resonance (NMR) spectroscopy and gas sorption. Solid-state magic angle spinning (MAS) ${ }^{29} \mathrm{Si}$ NMR experiments were performed on xerogel samples at $39.7 \mathrm{MHz}$ using a Chemagnetics console interfaced to a Nicolet 1280 data station. The Chemagnetics MAS probe employed $7.5 \mathrm{~mm}$ ceramic rotors that were typically spun at $4000 \mathrm{~Hz}$. A $5 \mu \mathrm{s}$ pulse with a delay time of $120 \mathrm{~s}$ was used. Typically, 512 accumulations were taken. Tetramethylsilane (TMS) was used as an external reference 19,20

Nitrogen adsorption porosimetry was performed at $77 \mathrm{~K}$ and $\mathrm{CO}_{2}$ adsorption porosimetry was performed at $195 \mathrm{~K}$ using a

(19) Assink, R. A.; Kay, B. D. Colloids Surf, A: Physicochem. Eng. Aspects 1993, 74, 1-5.

(20) Assink, R. A.; Kay, B. D. J. Non-Cryst. Solid 1988, 107, 35-
1996, 8, 1682-1701. 279

(17) Vanbommel, M. J.; Wolde, T.; Bernards, T. N. M. J. Sol-Gel Sci. Technol. 1995, 2, 167-170.

(18) Brinker, C. J.; Scherer, W. G. Sol Gel Science, The Physics and Chemistry of Sol Gel Processing; Academic Press: New York, 1990. 40 . 
Micromeritics ASAP 2010 porosimeter (Micromeritics Inc., Norcross, GA). Samples (either hybrid xerogels or microporous silica) were outgassed at $150{ }^{\circ} \mathrm{C}$ for $12 \mathrm{~h}$ under ultra-highpurity helium. Typically, $30 \mathrm{~s}$ of equilibriation time was used and adsorption and desorption isotherms were obtained without measurable hysteresis. Information concerning the pore sizes and pore size distributions of the microporous silica has not been derived from the adsorption experiments because of limitations of available models.

As reported previously, permeation experiments were performed on membranes prepared by dip-coating the sols onto commercial asymmetric alumina supports. Tubular alumina supports with approximately a $5 \mathrm{~nm}$ pore size were obtained from U.S. Filter. Membranes were deposited by dip coating at a rate of $20 \mathrm{~cm} / \mathrm{min}$ in a nitrogen atmosphere. The membranes were dried at $150^{\circ} \mathrm{C}$ for $3 \mathrm{~h}$ and tested for helium permeability. The membranes were further heated at $300^{\circ} \mathrm{C}$ for $3 \mathrm{~h}$ (heating rate $1^{\circ} \mathrm{C} / \mathrm{min}$ ) to create secondary micropores by template pyrolysis. The performance of the membranes was tested in a single gas permeation testing system with a bubble flow rate meter, as described previously. ${ }^{21,22}$

\section{Molecular Modeling}

To understand the relationship between pore structure and the structural features of the template ligand, we need to estimate the size of the organic ligand and the volume that it occupies. Slonimskii et al. ${ }^{23}$ have estimated the volumes occupied by different organic molecules through consideration of the atomic radius and bond lengths of the atoms that comprise these molecules. Their results indicate that the volume occupied by a propyl methacrylate molecule $\left(\mathrm{H}_{2} \mathrm{C}=\mathrm{C}\left(\mathrm{CH}_{3}\right)\right.$ $\left.\mathrm{CO}_{2}\left(\mathrm{CH}_{2}\right)_{2} \mathrm{CH}_{3}\right)$ is approximately $150 \AA^{3}$, a value similar to that calculated by BIOSYM software using van der Waals radii (164 $\AA^{3}$ ). However, using this approach, Slonimskii et al. found that the volumes of molecules they calculated were always smaller than the actual volume obtained from density measurements of the corresponding polymers. For most polymers, the ratio of the estimated volume to the measured volume is approximately 0.68 ; for example, on the basis of density measurements, the volume of a propyl methacrylate repeat unit in poly(propyl methacrylate) is estimated as $221 \AA^{3}$. The discrepancy arises because their molecular model underestimates the excluded volume of that which results from inefficient packing of the repeat units of the polymers.

In this study, we developed an alternative molecular model to estimate the volume occupied by a propyl methacrylate ligand, and hence, the pore volume (and size) obtained by ligand removal. The model is based on the following assumptions: (1) the propyl methacrylate ligands are randomly dispersed in a relatively dense silica matrix; (2) because of the similarity in size of the template and the primary structural units of the silica host, the silica structure cannot conform precisely to the template ligands; (3) the transport-limiting pore size created by template removal corresponds to the smallest, projected cross-sectional area of the template ligand.

(21) Brinker, C. J.; Ward, T. L.; Sehgal, R.; Raman, N. K.; Hietala S. L.; Smith, D. M.; Hua, D. W.; Headley, T. J. J. Membr. Sci. 1993 $77,165-179$

(22) Brinker, C.J.; Sehgal R. Hietala S. I. Deshpande, R.; Smith D. M.; Loy, D.; Ashley, C. S. J. Membr. Sci. 1994, 94, 85-102

(23) Slonimskii, G. L.; Askadskii, A. A.; Kitaigorodskii, A. I. Vysokomol Soyed 1970, A12, 494-512.



Figure 2. Results of molecular simulations of the organic template ligand: Frequency of specific dimensions observed in the $X$ or $Y$ direction by projecting the model molecule propylmethylacrylate in the $X-Y$ plane. The different values are obtained by rotating the molecule in three dimensions in increments of $5^{\circ}$.

Our simulations were conducted using BIOSYM software. The propyl methacrylate (PM) molecule was used as a molecular model of the template ligand (see Figure 2 inset). We minimized the configurational energy of PM in a vacuum and rotated the molecule in three dimensions in increments of $5^{\circ}$; we then projected the propyl methacrylate molecule onto the $X-Y$ plane at each increment and measured the dimensions of the projection, $X_{i}$ and $Y_{i}$. The volume occupied by the model molecule in the silica matrix was estimated using an equivalent sphere model of diameter, $D$. $D$ was estimated by averaging $D_{i}$, where $D_{i}$ was obtained as $D_{i}=$ $\left(X_{i} Y_{i}\right)^{1 / 2}$. The volume of the equivalent sphere, and thus the volume occupied by a model molecule in the silica matrix, was estimated as $4 / 3 \pi(D / 2)^{3}$. Using this simulation, the volume occupied by the propyl methacrylate molecule is calculated to be $209 \AA^{3}$, close to that calculated by Slonimskii et al. on the basis of polymer density $\left(221 \AA^{3}\right)$. Presumably, this approach still underestimates slightly the excluded volume/finite size effects, but it appears to be a reasonably accurate method of determining the ligand volume.

According to our assumption above, the smallest projected cross-sectional area of the propyl methacrylate ligand determines the pore size that governs gas permeation. This dimension can be obtained by tabulating the dimensions of the rotating model molecule in either the $X$ or $Y$ direction $\left(X_{i}\right.$ or $\left.Y_{i}\right)$. Figure 2 shows a frequency distribution of $X_{i}$ or $Y_{i}$ observed. From Figure 2 , we see that the distributions cut off at 5.1 $\AA$ and the smallest dimension observed is $\sim 5.2 \AA$. Thus, we predict the transport-limiting pore size to be $\sim 5.2 \AA$, if the pores do not collapse upon removal of the organic templates. Experimental measurements were conducted to test this model.

\section{Experimental Results and Discussion}

The porosity of the microporous silicas prepared by our organic templating approach includes two components: the porosity of hybrid materials before pyrolysis 


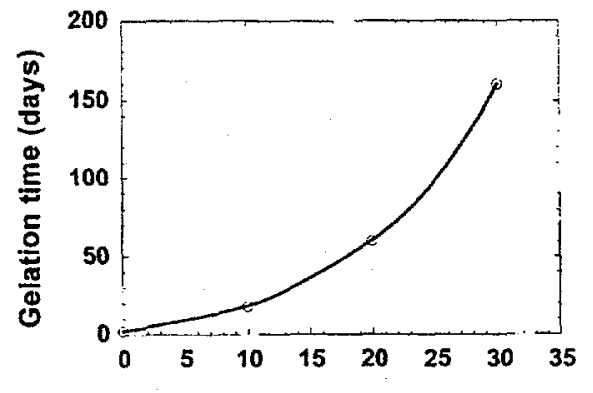

Mole ratio of MPS added to TEOS (\%)

Figure 3. Gelation time of the hybrid MPS/TEOS composite vs the amount of MPS added.

Table 1. $T$ and $Q$ Distributions of Si Atoms Obtained from ${ }^{29}$ Si NMR Experiments on MPS/TEOS Hybrid Materials Containing Different Amounts of MPS

\begin{tabular}{ccccccccc}
\hline $\begin{array}{c}\text { MPS } \\
\text { (mol \%) }\end{array}$ & $T^{2}$ & $T^{3}$ & $Q^{2}$ & $Q^{3}$ & $Q^{4}$ & $Q^{3}+T^{3}$ & $Q^{2}+T^{2}$ & $\mathrm{Si}-\mathrm{O}-\mathrm{Si}^{a}$ \\
\hline 0 & & & 6.2 & 48.4 & 45.4 & 48.4 & 6.2 & 84.8 \\
10 & 2.8 & 8.3 & 8 & 44.4 & 36.5 & 52.7 & 10.8 & 81.4 \\
20 & 6 & 14 & 6.4 & 42.4 & 31.2 & 56.4 & 12.4 & 79.7 \\
40 & 9.3 & 35.0 & & 28.9 & 26.8 & 63.9 & 9.3 & 79.4
\end{tabular}

a Percentage of bridged siloxane is calculated assuming each $\mathrm{Si}$ atom contains four covalent bonds.

(primary porosity) and that created by pyrolysis of the organic ligands (secondary porosity). Primary porosity is determined by the molecular structure of the hybrid nanocomposite, while secondary porosity is controlled by the amount of organic template ligands added, ligand size, and the distribution of the ligands in the hybrid matrix. The following section discusses the structure of the hybrid nanocomposites and resulting microporous materials and provides an interpretation of the structure in the context of primary and secondary porosity.

4.1. Structure of the MPS/TEOS Hybrid Nanocomposites. We prepared (x)MPS/ $1-x)$ TEOS xerogels with values of $x$ ranging from 0 to 0.4 . By substituting trifunctional MPS for tetrafunctional TEOS, we lower the tendency for condensation and cross-linking reactions, both by decreasing the total number of reactive functional groups and (because of the bulky nature of the methacrylpropylate ligand) by increasing the steric hindrance to polymerization reactions. As shown in Figure 3, this substitution results in a dramatic increase in the gelation time, corresponding to a dramatic decrease in the siloxane condensation rate.

MAS ${ }^{29} \mathrm{Si}$ NMR spectroscopy was used to determine the extent of condensation of the tri- and tetrafunctional silicon species and to determine the overall extent of condensation of the hybrid nanocomposites as a function of the MPS mole fraction. Table 1 shows the $Q$ and $T$ distributions of silicon atoms in MPS/TEOS hybrid nanocomposites. $Q$ is the designation for structural units in which the silicon atom is bonded to four oxygen atoms (i.e., silicon atoms from TEOS). $T$ is the designation for structural units in which the silicon atom is bonded to three oxygen atoms and one carbon atom (i.e., silicon atoms from MPS). The superscript on $Q$ or $T$ represents the number of siloxane bonds attached to the silicon atom. Table 1 shows that $Q^{4}$ and $Q^{3}$ concentrations decrease while $T^{3}, T^{2}$, and $Q^{3}+T^{3}$ contributions
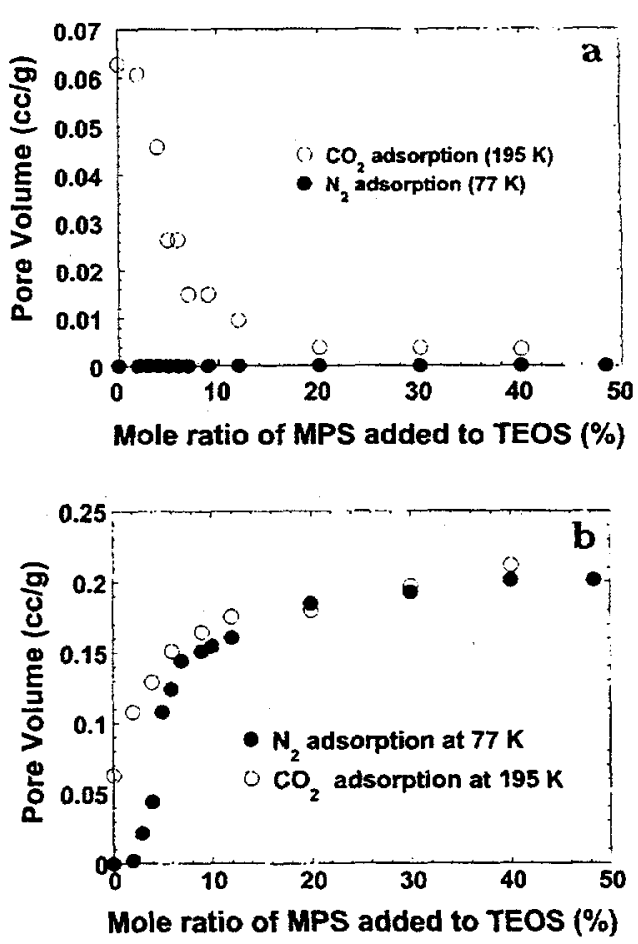

Figure 4. Pore volumes of the hybrid MPS/TEOS xerogels containing different amounts of MPS, before (a) and after (b) calcination. These data were obtained by $\mathrm{N}_{2}$ adsorption measurements at $77 \mathrm{~K}$ and $\mathrm{CO}_{2}$ adsorption measurements at $195 \mathrm{~K}$, respectively.

increase with increasing amounts of MPS substitution. The overall percentage of the bridging siloxane (-O$\mathrm{Si}-\mathrm{O}-$ ) bonds decreases from about 85 to $79 \%$ as the mole percent MPS increases from 0 to $40 \%$, which may promote structural relaxation or sintering of MPS/TEOS hybrid materials. $T$ components disappear through conversion to $Q$ components upon calcination, indicating the removal of the organic ligands. (Data are not shown here.)

Figure 4a shows the pore volumes of the MPS/TEOS hybrid nanocomposites prior to pyrolysis determined from $\mathrm{N}_{2}$ adsorption at $77 \mathrm{~K}$ and $\mathrm{CO}_{2}$ adsorption at 195 $\mathrm{K}$. We see that for all the hybrid specimens there is no porosity accessible to $\mathrm{N}_{2}$, whereas the $\mathrm{CO}_{2}$ accessible porosity decreases over the range 0-20\% MPS and remains at a small finite value at higher MPS concentrations. $\mathrm{CO}_{2}$ isotherms (not shown) were all of type I and indicative of microporosity. Because the kinetic diameter of $\mathrm{N}_{2}(3.64 \AA)$ is very similar to that of $\mathrm{CO}_{2}$ $\left(3.3 \AA\right.$ ), we believe that the different $\mathrm{N}_{2}$ and $\mathrm{CO}_{2}$ adsorption behaviors are a consequence of thermally activated transport in the primary micropore network of the hybrid nanocomposites: ${ }^{24}$ the higher temperature of the $\mathrm{CO}_{2}$ adsorption experiment overcomes the kinetic limitations of molecular diffusion, allowing $\mathrm{CO}_{2}$ to access the primary microporosity. As we show later, we can use $\mathrm{CO}_{2}$ and $\mathrm{N}_{2}$ sorption to distinguish between primary and secondary porosity in the calcined specimens.

(24) Greg, S. J.; Sing, K S. W. Adsorption, Surface Area and Porosity; Academic Press: New York, 1982. 


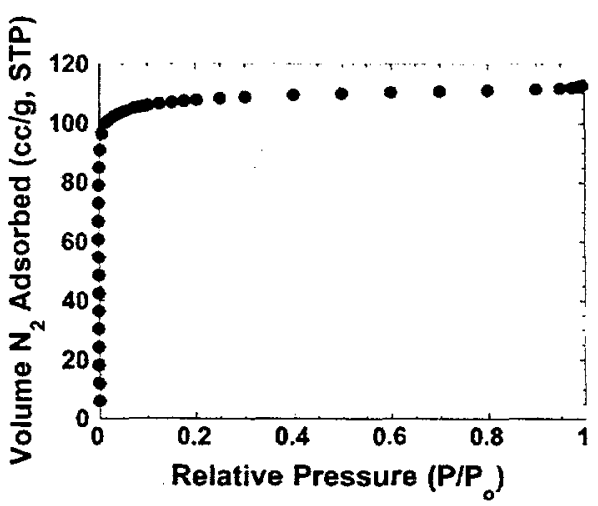

Figure 5. Nitrogen adsorption isotherms (at $77 \mathrm{~K}$ ) of the microporous silica prepared by calcining the hybrid MPS/TEOS (20/80) nanocomposite.

The combined gelation time, NMR, and adsorption results suggest that increasing MPS concentrations promote collapse of the hybrid gel network during drying through a reduction in the siloxane condensation rate and correspondingly the extent of condensation at the gel point. Using a one-dimensional analysis of gel drying that accounts for evolving capillary stress and network modulus, we predict that, for a sufficiently low initial gel modulus, the gel network should collapse "completely" during drying (residual porosity related to entrapped solvent). Thus, we conclude that MPS additions progressively reduce the initial gel modulus. Beyond about 20\% MPS, the gel network can no longer resist the capillary stress and the network collapses (almost completely).

4.2. Structure of Microporous Silica Prepared by Template Pyrolysis. MPS/TEOS hybrid nanocomposites were heated at $350^{\circ} \mathrm{C}$ for $3 \mathrm{~h}$ to remove the organic template ligands and create secondary pores. Figure 5 shows a $\mathrm{N}_{2}$ adsorption isotherm of a $20 \%$ MPS hybrid nanocomposite after pyrolysis. The sharp type I isotherm indicates a microporous network and a narrow pore size distribution. ${ }^{24}$ Other porous xerogels prepared with different MPS/TEOS ratios also show similar, sharp type $\mathrm{I}$ isotherms. $\mathrm{CO}_{2}$ adsorption isotherms (195 $\mathrm{K}$ ) are similar in shape to $\mathrm{N}_{2}$ adsorption isotherms (data are not shown here; see discussion below).

Figure $4 \mathrm{~b}$ shows the pore volumes of MPS/TEOS xerogels (after pyrolysis) measured by $\mathrm{N}_{2}$ and $\mathrm{CO}_{2}$ adsorption experiments. A comparison of Figure 4, parts $a$ and $b$, shows that template pyrolysis creates $a$ secondary network of micropores that is accessible to $\mathrm{N}_{2}$ sorption. This secondary $\left(\mathrm{N}_{2}\right.$ accessible) porosity equals zero for $0 \%$ MPS and $2 \%$ MPS, increases steeply for MPS concentrations up to about $7 \%$ MPS, and increases more gradually above about $10 \%$ MPS.

Since both the primary and secondary pores are accessible to $\mathrm{CO}_{2}$, the $\mathrm{CO}_{2}$ pore volumes of the pyrolyzed xerogels are greater than the $\mathrm{N}_{2}$ pore volumes for the samples (those prepared with less than 20\% MPS) that showed any appreciable primary porosity. When the primary porosity becomes negligible, $\mathrm{CO}_{2}$ and $\mathrm{N}_{2}$ pore volumes tend to be identical, demonstrating that, in these cases, we can prepare microporous silica containing only the desired secondary porosity.

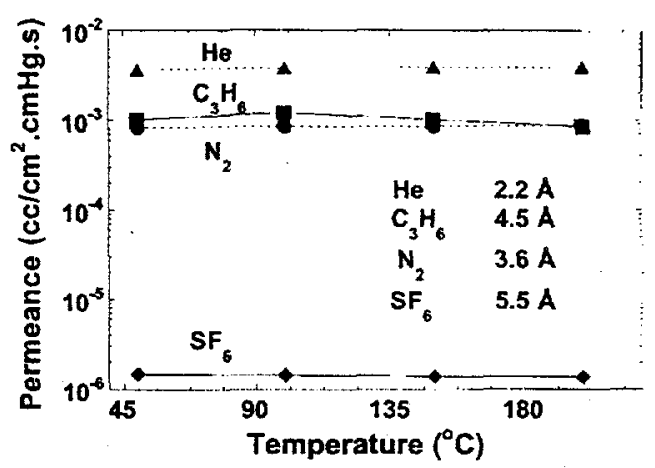

Figure 6. Permeation measurements of the microporous silica membrane prepared by calcining the hybrid MPS/TEOS (20) 80) membrane coated on a $\gamma$-alumina porous support. The permeation data were obtained at different temperatures using the series of gases, $\mathrm{SF}_{6}, \mathrm{C}_{3} \mathrm{H}_{6}, \mathrm{~N}_{2}$, and $\mathrm{He}$.

Figure 6 shows the gas permeation behavior of a microporous silica membrane prepared from a $20 \%$ MPS sol. The membrane was impermeable to helium before pyrolysis of the organic templates. As shown in Figure 6 , after pyrolysis, the flux of $\mathrm{SF}_{6}$ is 1000 times less than that of propene, and that of the other smaller molecules, nitrogen and helium. The kinetic diameters of $\mathrm{SF}_{6}$ and propene are 5.5 and $4.5 \AA, 25$ respectively, so it is reasonable to conclude that the membrane has a transport-limiting pore diameter larger than $4.5 \AA$ and smaller than $5.5 \AA$. As discussed above, when the amount of MPS added is greater than about $20 \mathrm{~mol} \%$, the primary porosity is negligible, so the micropore network in the membrane consists mainly of secondary pores. In the discussion below, we compare the secondary pore size derived from permeation experiments to that predicted by simulation in order to establish the structure-property relationships needed to enable custom design of microporous membranes.

4.3. Relationship between Pore Structure and the Template Ligand Structure. 4.3.1. Pore Size. Comparison of the ligand size obtained from computer simulation results (ligand equivalent diameter $\sim 5.2 \AA$, see section 3 ) and the pore size obtained from membrane transport experiments $(4.5 \AA<$ pore diameter $<5.5 \AA$ ) suggest that for the 20\% MPS hybrid system there is a close correspondence between the template ligand size and resulting secondary pore size. It should be emphasized, however, that this correspondence requires that secondary porosity be avoided and that template removal be accomplished with little perturbation of the host silica network. The efficacy of the templating approach must therefore be evaluated on a case-by-case basis.

4.3.2. Pore Volume. The volume occupied by one propyl methacrylate molecule, as estimated by molecular simulation, is $209 \AA^{3}$, corresponding to a molar volume of $125.4 \mathrm{~cm}^{3}\left(N \times 209 \mathrm{REM} \AA^{3}\right)$, assuming the ligands to be unassociated. On the basis of a linear mixing model, the volume fraction of the template ligands $\phi_{\mathrm{T}}$ (calculated porosity) in a dense XMPS $\cdot(1-$ $X)$ TEOS hybrid is estimated to be

(25) Breck, D. W. Zeolite Molecular Sieves, Structure Chemistry and Use; Wiley and Sons: New York, 1973. 


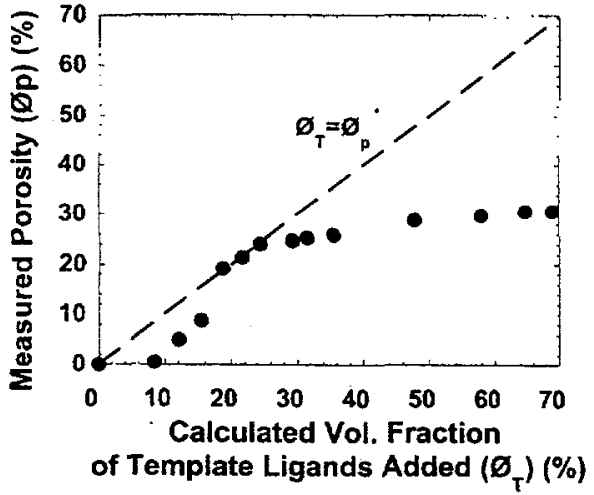

Figure 7. The volume fraction of the measured secondary pores ( $\phi_{\mathrm{P}}$ ) obtained by $\mathrm{N}_{2}$ adsorption measurement at $77 \mathrm{~K}$ vs the calculated volume fraction of organic ligands added to silica matrix $\left(\phi_{\mathrm{T}}\right)$.

$$
\begin{aligned}
& \phi_{\mathrm{T}}=\frac{X\left(125.4 \mathrm{~cm}^{3} / \mathrm{mol}_{\mathrm{L}}\right)}{X\left(125.4 \mathrm{~cm}^{3} / \mathrm{mol}_{\mathrm{L}}\right)+1 / \rho_{\mathrm{S}}\left(60.0 \mathrm{~g} / \mathrm{mol}_{\mathrm{S}}\right)}= \\
& \frac{2.09 X}{2.09 X+1 / \rho_{\mathrm{S}}}
\end{aligned}
$$

where the subscripts $\mathrm{L}$ and $\mathrm{S}$ refer to ligand and silica, respectively, and the silica matrix is assumed to be fully condensed with a density $\rho_{\mathrm{S}}=2.2 \mathrm{~g} / \mathrm{cm}^{3}{ }^{18}$ Assuming that pores do not collapse during pyrolysis, the ideal secondary pore volume fraction $\phi_{\mathrm{P}}$ should equal $\phi_{\mathrm{T}}$.

Figure 7 compares the volume fraction of the measured secondary porosity $\phi_{\mathrm{P}}$ (calculated from the pore volume measured by nitrogen adsorption) with $\phi_{\mathrm{T}}$. We see that for $\phi_{\mathrm{T}}<10 \%$, $\phi_{\mathrm{P}}$ equals zero. Then, with increasing $\phi_{\mathrm{T}}, \phi_{\mathrm{P}}$ increases gradually then sharply above $\phi_{\mathrm{T}}=16 \%$. In the range of $18 \%<\phi_{\mathrm{T}}<25 \% ; \phi_{\mathrm{T}}=\phi_{\mathrm{P}}$. Above $25 \%, \phi_{\mathrm{P}}$ increases only slightly with $\phi_{\mathrm{T}}$. The observation of a sharp increase in the accessible secondary porosity with increasing $\phi_{\mathrm{T}}$ is suggestive of percolation behavior. ${ }^{26}$ If the template ligands are randomly distributed in the silica matrix and completely removed by pyrolysis to create secondary pores, we would expect pore connectivity at a critical pore volume fraction $\phi_{C}$ of 16\%-manifested as a sudden "jump" in the accessible secondary porosity. When $\phi_{\mathrm{T}}$ is less than $16 \%, \phi_{\mathrm{P}}$ is expected to be zero because of the lack of pore connectivity. In our case, the small finite accessible porosity observed below $\phi_{\mathrm{C}}$ is due to the contribution of secondary pores that connect to the outside surface of the sample particles. For ligand volume fractions greater than $\phi_{\mathrm{C}}$ we would expect (from percolation theory) the fraction of accessible secondary porosity to increase gradually, as more secondary pores become connected to the spanning secondary pore network. The observation that $\phi_{\mathrm{P}}=\phi_{\mathrm{T}}$, in the range $18 \%<\phi_{\mathrm{T}}<25 \%$, may imply therefore that (incipient) phase separation occurs for these concentrations of template ligands, providing access to all the secondary micropores. Alternatively, this could be a finite particle size effect as described above.

For volume fractions of template ligands above about $25 \%$, we find $\phi_{\mathrm{P}}<\phi_{\mathrm{T}}$ and observe that the volume

(26) Sahimi, M. Applications of Percolation Theory; Taylor \& Francis, Inc.: London, 1994. a
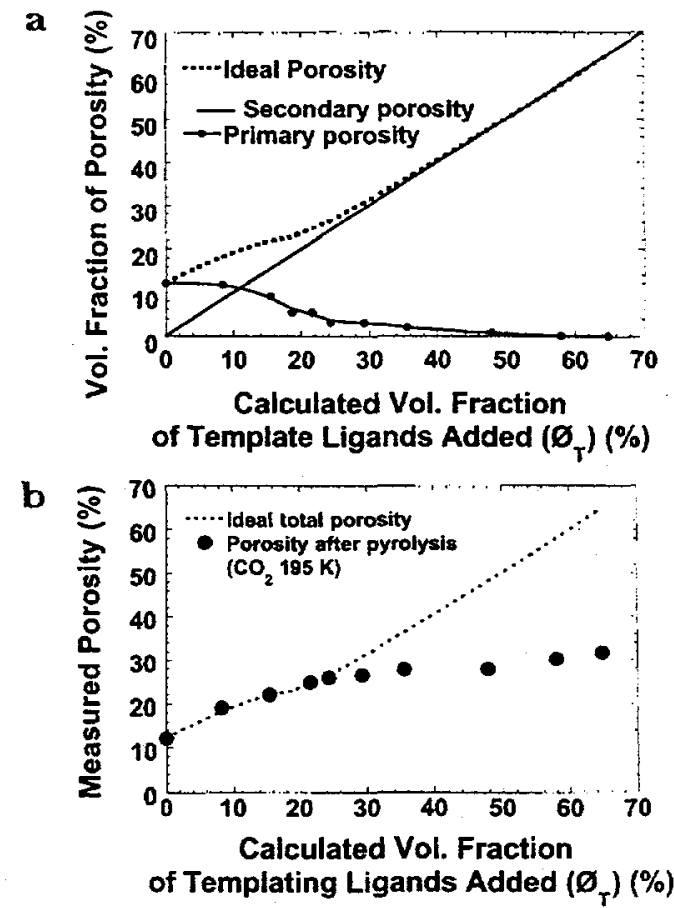

Figure 8. Additional properties of primary porosity and secondary porosity examined by $\mathrm{CO}_{2}$ adsorption experiments at $195 \mathrm{~K}$. (a) Ideal total porosity estimated by adding the contribution of primary porosity and secondary porosity. (b) Total porosity measured from pore volume obtained by $\mathrm{CO}_{2}$ adsorption measurements compared with the ideal total porosity.

fraction of secondary porosity is limited to about $30 \%$. This limitation is due a progressive weakening of the network with increasing template ligand additions. The ${ }^{29}$ Si MAS NMR results shown in Table 1 indicate a reduction in the overall amount of condensation with ligand addition and a substantial increase in structurally flimsy difunctional $Q^{2}+T^{2}$ groups. This lower connectivity of the silica network with increasing $\phi_{\mathrm{T}}$ promotes its densification during template pyrolysis (via structural relaxation, further condensation, and conceivably viscous sintering). The result is that, beyond about 46 vol \% template ligand addition, there is no measurable increase in the volume fraction of accessible secondary porosity.

Figure 8a shows the ideal total porosity estimated by adding the contributions of primary and secondary porosity, assuming that all porosity is detectable by $\mathrm{CO}_{2}$ adsorption at $195 \mathrm{~K}$ and there is no loss of porosity during pyrolysis. The ideal total porosity in Figure 8a suggests that the total porosity increases with the amount of organic ligands added and is almost identical to the secondary porosity once the percolation threshold is exceeded. The ideal total porosity at $0 \mathrm{vol} \%$ MPS is not zero because of the presence of primary porosity. Figure $8 \mathrm{~b}$ compares the measured total porosity (determined from $\mathrm{CO}_{2}$ adsorption measurements) with the ideal total porosity. The observation that the ideal and measured total porosity are equal below $25 \mathrm{vol} \%$ MPS implies that the primary porosity is retained in the pyrolyzed microporous silica and that the primary and secondary pore networks are interconnected (otherwise 
the secondary pores would remain inaccessible below $\left.\phi_{\mathrm{C}}\right)$. Thus, the microporous network below $\phi_{\mathrm{C}}$ can be envisioned to comprise larger secondary pores connected by smaller primary pores. In this situation, the transportlimiting pore size should be that of the primary pores, while the interconnected secondary pores should contribute to the enhanced flux, an interesting combination of transport properties for membrane applications.

\section{Conclusions}

Microporous silica materials with a small pore size and a narrow pore size distribution can be obtained by pyrolysis of propylmethylacrylate ligands from relatively dense hybrid nanocomposites. The porosity of the template-derived microporous silica consists of smaller primary micropores and larger secondary micropores that are distinguished by $\mathrm{N}_{2}$ and $\mathrm{CO}_{2}$ adsorption experiments, respectively. Primary porosity decreases with the amount of organic template ligands added because of enhanced densification of the hybrid materials during drying.

Using molecular simulations, we have estimated the secondary pore size and pore volume created by template ligand removal. Comparison of the estimated pore size and the pore size determined from gas permeation experiments performed on supported membranes reveals a close correspondence of the template ligand size to the secondary pore size. Comparison of the estimated and measured secondary pore volumes shows that the secondary microporosity is inaccessible when the template ligand volume fraction is below a critical percolation threshold, $\phi_{\mathrm{C}}=16 \mathrm{vol} \%$. The observation of percolation behavior implies that the organic ligands are randomly dispersed in the silica nanocomposite. Above $\phi_{C}$ we observe a limited compositional range where the volume fraction of accessible secondary porosity equals that of the template ligands. Template ligand additions above about $25 \mathrm{vol} \%$ result in little additional secondary porosity because of a partial collapse of the silica network accompanying template pyrolysis. The extent of collapse depends on the extent of condensation of the network at the pyrolysis temperature, so increasing concentrations of trifunctional MPS cause progressively greater loss of secondary porosity. Further experiments are underway using bridged template ligands, for example, $(\mathrm{RO})_{3}-\mathrm{Si}-\mathrm{R}^{\prime}-\mathrm{M}(\mathrm{OR})_{3}$ in an attempt to further reduce the secondary pore size for applications such as air separation and natural gas purification.

Acknowledgment. This work was supported by the Center for Micro-Engineering Materials at the University of New Mexico, the DOE Federal Energy Technology Center, the Electric Power Research Institute, and National Science Foundation (CTS-9624841). Sandia National Laboratories is a U.S. DOE facility operated under Contract No. DE-AC04-94AL 85000.

CM980517Y 